DOI: $10.17516 / 1997-1370-0556$

УДК 314.151-054.73(450)

\title{
Intercultural Mediation Addressed to Refugees and Asylum Seekers in Italy
}

\author{
Federico Zannoni \\ University of Bologna \\ Bologna, Italy
}

Received 18.12.2019, received in revised form 13.01.2020, accepted 10.02.2020

\begin{abstract}
Starting from a preliminary definition of the concept of mediation and its possible applications, this article aims to deepen the concept and practice of intercultural mediation. After an analysis of the reality of multicultural society in Italy and of the phenomenon of the arrival of refugees and asylum seekers from Africa, we will move on to presenting the principles and good practices of intercultural mediation implemented in the reception and integration services. Finally, the results of a research carried out within the services of the city of Reggio Emilia, in particular through group discussions with young men seeking asylum, guests of some residential structures, will be presented.
\end{abstract}

Keywords: intercultural mediation, migration, refugees and asylum seekers, Italy.

Research area: social sciences.

Citation: Zannoni, F. (2020). Intercultural mediation addressed to refugees and asylum seekers in Italy. J. Sib. Fed. Univ. Humanit. Soc. Sci., 13(2), 246-257. DOI: 10.17516/1997-1370-0556.

\section{A preliminary definition: \\ Mediation}

According to the United Nations (United Nations, 2012: 4), "mediation is a process whereby a third party assists two or more parties, with their consent, to prevent, manage or resolve a conflict by helping them to develop mutually acceptable agreements". This definition opens to a wide range of specifications: at first, the two conflicting parties can be represented by single persons or groups of people, they can have equal or non equal status and power, they can or cannot know each other in deep. The reasons of the conflict can be or cannot be clearly defined, since they involve a eterogeneous range of implicit and explicit factors and characterisations, moving from unconscious prejudices and hostility to concrete goals and desired objects. Mediation aims to create the conditions to manage the conflict through increasing and mutual cooperation, producing outcomes that can be limited in scope, dealing with a specific issue, or can tackle a broad range of issues in a comprehensive peace agreement.

It deals with complexity and vulnerability of human relations, offering a professional and specialised approach.

(C) Siberian Federal University. All rights reserved

* Corresponding author E-mail address: smololga@mail.ru 
A good mediator promotes exchange through listening and dialogue, engenders a spirit of collaboration through problem solving, ensures that negotiating parties have sufficient knowledge, information and skills to negotiate with confidence and broadens the process to include relevant stakeholders from different segments of a society. Mediators are most successful in assisting negotiating parties to forge agreements when they are well informed, patient, balanced in their approach and discreet (United Nations, 2012: 5).

Mediation assumes different caracteristics and is strictly linked to the specific situations, anyway flexibility, creativity and the focus on the future are transversal and required elements. Similarly, although mediators may have different "styles", their roles commonly include (Blaney McMurtry, 2019):

1. Setting the tone for joint problem-solving by estab3lishing and maintaining a rational and productive atmosphere for negotiation.

2. Encouraging full disclosure of information.

3. Assisting the parties to understand each other's perspectives (needs, concerns, values, fears) and trying to build empathy between the parties.

4. Facilitating communication between the parties by keeping the discussions "civil"; allowing parties to vent if appropriate; taking the "sting" out of loaded or angry statements by, for example, reframing them in neutral way or in a way which reveals the underlying interest.

5. Maintaining balance in the process by ensuring that the parties have an equal opportunity to speak.

6. Identifying and seeking clarification of misunderstandings, assumptions, and discrepancies.

7. Probing for interests underlying positions taken by the parties in order to expand the opportunity for creative solutions.

8 . Assisting parties to identify common interests.
9. Assisting the parties to explore and assess their alternatives to a negotiated resolution.

10. Acting as a "reality check" by challenging parties on their positions (usually in caucus) and by reminding them of the costs of not settling.

11. Assisting the parties to generate options for settlement and to develop criteria by which to evaluate those options.

12. Assisting the parties to evaluate the advantages and disadvantages of each option and encouraging the selection of an option which maximizes satisfaction of both of their interests.

13. Keeping the parties focused on the future and their goal of resolving the dispute. 14. Maintaining optimism that an agreement can be reached and sustaining commitment to assist parties achieve resolution.

We can identify four different approaches of mediation (facilitative, formulative, power based, transformative), all of them aimed to address and resolve conflicts in a constructive and non-violent manner. The facilitative mediation focuses on organising and facilitating communication between the parties in a non-directive manner, eliciting the underlying interests and needs behind the stated demands and positions; in order not to jeopardise multi-partiality, the mediator refrains from making substantial recommendations or suggestions. In formulative mediation, the mediator takes a more directive role and, in addition to structuring the process and gathering proposed solutions, offers different options with the consent of the parties. The focus of power-based mediation lies in using the mediator's leverage in order to reach an agreement through his power and strategic tactics, threats of punishment and promises of reward. The transformative mediation aims to transform the disputants, both individually and in relation to one another, through "empowerment" (disputants improve or learn new skills to resolve their own disputes) and "recognition" (understanding the other side's perspective, thereby creating "empathy" for the other).

The differences between these approaches are not always a clear-cut and they can be 
mixed and contestualised in original combinations by the different mediation actors (Initiative Mediation Support Deutschland, 2017).

\section{Approaches to Intercultural mediation}

Mediation can be applied in different arenas and contexts: families, workplaces, communities, public sector, faith communities, educative environments, neighbourhoods, and so on. In this article we aim to focus on a particular type on mediation that reflects and faces one of the main characterisations of communities in Italiy and Western world: we are focusing on intercultural mediation addressing the management of diversity and conflicts in multicultural societies. Quoting Vladimir Fokin et al. (Fokin et al., 2016: 10777).

Modern society is characterized by a high degree of social and cultural mobility, an increase of migration flows and an interaction of cultures of different nations. As a result of this process, most communities have lost their traditional ethnic and cultural homogeneity and acquired the multicultural character, i.e. have become culturally diverse. This situation gave rise to the problem of ensuring the stability of communities in the context of cultural and ethnic diversity.

Social cohesion in multicultural contexts has to be built and maintained on a multifaced social capital, weakly sustained by diversity, new knowledge and relationships. New spaces of dynamic divergence and people's reflection on and reconsideration of themselves and their words are pushed by the encounter with diversity; in this context, mutual understanding, reflexivity and effective communication patterns have to be enhanced through acts of mediation and negotiation of differences (Arvantis, 2014).

Diversity in multicultural society is dynamic and is grounded on group interactions which are constituted through relationships in which one group is defined in relation to another (Kalantzis and Cope, 2012); it is defined by complex dimensions of differences: material (social class), corporeal (age, race, sex and sexuality, physical and mental capacities) and symbolic (socially constructed realities of culture or ethnicity, language, gender, affinity). Diversity and differences express themselves in everyday life experiences, mostly through implicit sets of habits, behaviours, values and interests, involving people with different cultural background in perpetual intercultural communicative actions, whose effectiveness depends on the level of negotiation and sensitivity on cultural differences, considering aspects as cultural styles, orientiation to space and time, gender differentiation or power distances. Referring to the Lefebvre's unitary theory of space (1991), the interaction with people with different culture impacts on three levels: on the physical (real/material) or perceived space, on the mental (imagined/conceptual) or conceived space and on the social or lived space (Rick, 1997), where "our perceived and conceived notions of space meet, are contested, combined and altered" (Skordoulis and Arvanitis, 2008: 108). The result of the intercultural encounter is the recombination of different cultural elements populating a third, interstizial space between cultures (Bhabha, 1994).

Intercultural mediation works on the processes of lifeworld construction, sharing and redefinition of values, beliefs and principles that develop in these newly formed interstizial spaces, promoting the creation of a larger, flexible and tolerant third culture context (Townsend, 2002; Thomas, 1996). It is "closely intertwined with the concept of interculturality and embraces a culture of reciprocity and responsiveness to the specificities of diverse migrant groups based on interdependence and cooperation between cultural groups, individuals and institutions" (Arvantis, 2014, p. 10). Interculturality is based on and aimed to reciprocity, dialogue and mutual understanding, but at the same time it considers and accepts that cultural systems may be incompatible and contradictory resulting in conflict (Panikkar, 1995). Intercultural mediation should prevent and manage conflicts, building bridges for reciprocal adaptation through processes of reciprocal and mutual act of understanding, reflexive action and collaborative practices that promote the transformation of individuals and systems and the construction of spaces of social interactions 
where new traits of sociability (new relations and communication patterns) are developed.

In Euroopean and Italian contexts the need for intercultural mediation is associated to "migrant influx and the difficulties faced by social institutions and professionals to adapt their interventions to specific integration or settlement needs" (Arvantis, 2014: 2). Intercultural mediation has to deal with the social fragmentation and the marginalization that affect socially excluded groups; it facilitates the access to public services and "assists both migrants to find their way in the new country and social actors and institutions to better understand migrant settlement needs and communicate in a respectful manner with them" (Cohen-Emerique, 2007: 8).

Margalit Cohen-Emerique (Cohen-Emerique, 2007: 11-14) has identified four types of intercultural mediation:

1) The liaison type is focused on the empowerment of the communication between parties. It facilitates the access to public services and ensures that social actors consider and respond to the needs of migrant groups.

2) The second type is interested in facing and dissolving cultural misunderstandings due to ignorance, prejudice, discrimination or stereotyping, by providing culturally appropriate information.

3) The model of the conflict management and resolution consider diversity as a new kind of non-fixed capital that can be harnessed as an asset for the society as a whole (Kalantzis \& Cope, 2012). 4) The last type refers to "a process of transformation of institutional approaches, norms, structures and regulations as well as personal beliefs in the context of mutual understanding, collaboration and trust. Here intercultural mediators act as agents of change and their expertise and competency is being recognised and valued by both parties" (Arvantis, 2014: 3).

Researches (Cohen-Emerique, 2007: 14) evidences that the liason type is the most frequently used, while the other types are finding more resistance because they would imply significant changes in the approaches and in the common practices of insititutions and professions. However, it is easy to demonstrate that the best approaches would be those that include and intertwine all the four types.

Jon Townsend (2002) identifies five principles that should be present in all the actions of intercultural mediation: flexibility, tolerance, hope, respect and reciprocity, inquisitiveness to learning. These same principles converge in the knowledge, skills and attitudes that define the intercultural competence as the multifaced ability for cultural exchange, interaction and symbolism, that allows not only to successfully communicate with people from other cultures, but to negotiate with the whole spectrum of diversity and otherness (Council of Europe, 2011; Stier, 2006).

\section{Migration \\ and multicultural society in Italy}

If we conbsider most of its history from the unity onwards, Italy has been mainly a country of emigration; it is estimated that between 1876 and 1976 over 24 million people left (Rosoli, 1978), with a peak in 1913 of over 870.000 departures, to the point that today we can define it the great emigration or Italian diaspora.

Throughout this period, if we don't consider the migration due to the consequences of the Second World War such as the Istrian exodus or the return of Italians from the former African colonies, the phenomenon of immigration had been practically non-existent. These phenomena were episodic in nature and did not present substantial integration problems from a social or cultural point of view. Italy tended to remain a country with a negative migration balance; the phenomenon of emigration began to weaken decidedly only starting from the Sixties, after the years of the economic miracle.

In particular, in 1973, Italy had for the first time a very slight positive migration balance (101 entries for every 100 expatriates), a characteristic that would become constant, amplifying itself in the years to come. It should be noted, however, that in this period the entrances were still largely made up of Italian emigrants returning to the country, rather than to foreigners. The flow of foreigners began to take shape only towards the end of the Seventies, both for the "open door policy" practiced by Italy, and for more restrictive policies adopted 
by other countries. In 1981, the first Istat census of foreigners in Italy calculated the presence of 321.000 foreigners, of which about one third were "stable". A year later, in 1982 a first regularization program for undocumented immigrants was proposed, while in 1986 the first law was passed (law 30 December 1986, n. 943) with which the objective was set to guarantee to the non-EU workers the same rights of the Italian workers. In 1991 the number of foreign residents was doubled, to 625.000 units.

In the Nineties, the migration balance has continued to grow and, since 1993 (the year in which the natural balance became negative for the first time), has become solely responsible for the growth of the Italian population. In 1990 the so-called Martelli law was issued and for the first time a planning of entry flows was introduced, in addition to an amnesty for those who were already in Italian territory: around 200.000 foreigners were regularized, mainly from North Africa.

In 1991 Italy had to deal with the first "mass immigration", from Albania (originating from the collapse of the communist bloc), resolved with bilateral agreements. In the following years further bilateral agreements will be signed with other countries, mainly in the Mediterranean area. According to data estimated by Caritas, in 1996 there were 924.500 foreigners in Italy.

The Turco-Napolitano law was issued in 1998, aiming to regulate incoming flows, discourage illegal immigration and establishing, for the first time in Italy, temporary detention centers for those foreigners "subjected to expulsion orders ". However, the matter will again be regulated in 2002, with the so-called Bossi-Fini law, which also provided for the possibility of immediate expulsion of illegal immigrants by the public security force (Militello and Spena, 2015). At the time of the 2001 census of the population, 1.334.889 foreigners were present in Italy: the most represented communities were the Moroccan (180.103 persons) and Albanian (173.064) (Istat, 2001).

According to Istat data on the national demographic balance, on 31 December 2017, 5.144.440 foreign citizens were regularly resident in Italy, equal to $8,5 \%$ of the total resident population (60.483.973) (Istat, 2017), virtually unchanged from the previous year $(+0.42 \%)$ (Istat, 2016). Analyzing the countries of origin of foreign citizens who are regularly resident, we note that in recent years there has been a marked increase of flows from Eastern Europe, which exceeded those relating to the countries of North Africa, which were the majority until the 1990s. This is mainly due to the rapid increase of the Romanian community in Italy, which, in particular in 2007 , has roughly doubled, going from 342.000 to 625.000 people and thus representing the main foreign community. This probably depended on Romania's entry into the European Union, which facilitated flows, and on linguistic affinity.

According to Istat data, on 1 January 2016, almost 1.2 million Romanian citizens resided in Italy, accounting for $23 \%$ of the foreign population and about $1,97 \%$ of the total resident population in Italy; this means that almost $45 \%$ of expatriate Romanian citizens residing in the European Union reside in Italy. Alongside Romanians, the main foreign communities in Italy are the Albanian $(9,3 \%$ of the foreign population), Moroccan (8,7\%), Chinese $(5,4 \%)$ and Ukrainian (4,65\%). On 1 January 2016, just over $30 \%$ of foreign residents are citizens of an EU country, and over $50 \%$ are citizens of a European country. Both the citizens of African countries and Asian countries are about $20 \%$ of the total (Istat, 2017).

\section{Irregular migrants, refugees and asylum seekers}

In 2011, following the "Arab Spring" riots that broke out in various countries, Italy welcomed 63.000 migrants arriving on its shores, mainly from Tunisia and Libya. But the most significant increase occurred in 2014, with the arrival of 170.000 people on the coast of the peninsula, which led to an increase of about $400 \%$ compared to the arrivals of 2013 . This growth was mainly determined by the tightening of conflicts in Africa and in the Middle East, primarily the war in Syria. In fact, most of the people were refugees fleeing conflict and persecution, therefore entitled to protection under international law. Most of these fleeing people crossed the sea in inhuman conditions, 
often in the hands of traffickers, making the Mediterranean route the scene of a silent massacre.

Following the tragic shipwreck of a boat near the island of Lampedusa in October 2013, in which 368 people lost their lives, the Italian government decided to start a maritime search and rescue operation called Mare Nostrum. This military and humanitarian operation was undertaken with the aim of ensuring rescue at sea for migrants arriving up to $120 \mathrm{~km}$ from the Italian coast, reducing the incidence of deaths that until the previous year on the Libyan route were estimated at 1 for every 17 disembarked, while in the period of the Mare Nostrum operation this estimate decreased to 1 in every 50. Mare Nostrum ended in November 2014, to be replaced by Triton, a more contained and less resourceful operation, led by the European Agency FRONTEX.

In the first four months of 2015 the number of deaths at sea reached a new peak: in the mentioned period, in fact, almost 1800 drowned or disappeared migrants were registered. To deal with these latest tragedies, European leaders have decided to triple the funding for Operation Triton, increasing its range of action in international waters, with a consequent decrease in deaths at sea. Although the total number of people fleeing the Mediterranean route has continued to grow dramatically, the total number of arrivals on the Italian coast in 2015 decreased compared to the previous year, for a total of approximately 150.000 arrivals. This is due to the fact that the eastern Mediterranean route, from Turkey to Greece, has now surpassed that of the central Mediterranean, from North Africa to Italy, becoming the main source of arrivals by sea. People arriving by sea in Greece in 2015 reached a number of about 830.000, mainly Syrians and Afghans.

At the end of 2014, the total number of refugees in Italy was 93.715 , in addition to the 45.749 asylum requests awaiting outcome. For the year 2014, the number of asylum requests was $63.700,148 \%$ more than in 2013 . The main country of origin of these applicants was Mali, followed by Nigeria, Gambia and Pakistan, but the greatest number of arrivals to Italy by sea corresponded to Syrian or Eritrean citizens. In fact, the number of arrivals by sea in 2014 was higher than the number of asylum applications submitted, as a result of the fact that many of those who landed preferred to continue their journey to apply for asylum in another country, in particularly in Sweden and Germany, where other family members often reside or in any case there is a strong presence of their national community, and where there are better prospects for integration.

Definitely, between January 2013 and July 2018, approximately 685.000 foreigners reached the Italian coasts by sea through irregular channels. Between 2014 and 2016, in particular, disembarkations have always exceeded 150.000. The situation has radically changed compared to the period 2002-2010, when disembarkations in Italy were around an average of 20.000 a year. The arrivals registered from 2013 to 2017 were almost 670.000 , more than triple of the 220.000 registered in the previous ten years (2003-2012) (Villa et al., 2018).

The reception system is divided into three phases: an initial phase of rescue, first assistance and identification; a first reception phase where the identification is completed and the asylum application is recorded; a last phase of secondary reception. Who arrives in Italy by sea is first of all welcomed in hotspots, set up following the European Agenda on Migration (2015). The hotspots are facilities located near the ports of landing, where the first aid and identification procedure take place. The stay times in these closed structures must be very short: after a maximum of 72 hours the migrants who have applied for asylum, the majority of those arriving by sea, must be transferred to the first reception centers. If, on the other hand, a request for protection is not presented, the migrant must be moved to identification and expulsion centers to start the procedures for repatriation.

The second phase of the reception system is mainly constituted by the Reception centers for asylum seekers, established in 2002 and whose legislation has developed over time, most recently with the DL 142/2015 art. 9 which reconfigures them into "government centers of first reception", and that the Italian Ministry Roadmap has renamed "regional hubs". 
The last phase, the one of the secondary reception, intended to facilitate the integration of the migrant, is constituted by the Protection system for asylum seekers and refugees (Sprar), established by law n. 189/2002 and most recently reformed with DL 142/2015, art.14. The aim is to offer "integrated reception projects". The Sprar structures are managed by the third sector in collaboration with local authorities, which access funding from the National Fund for asylum policies and services, which also includes funding from the Asylum Migration and European Integration Fund. Over the years, the places available for the Sprar system have actually increased, and to a considerable extent: from less than 4.000 in 2012 to around 25.000 in 2017. However, in absolute terms, the system is still far from offering a sufficient number of places compared to to requests for asylum. If in 2014 about one in three migrants were housed in Sprar facilities, now the proportion is one in 7. In order to encourage the municipalities to join the Sprar system, the decree of 10 August 2016 of the Ministry of the Domestic Affairs indicates new guidelines for the local authorities' access to funding. These simplify membership of the Sprar by local authorities, which can apply online at any time. Furthermore, to guarantee a fair distribution of migrants in the territory and to prevent some municipalities from having to take on an unsustainable number of asylum seekers and migrants with international protection, on 11 October 2016 the Ministry of the Domestic Affairs issued the directive for "the launch of a system for the gradual and sustainable distribution of asylum seekers and refugees", which gave rise in December 2016 to the distribution plan prepared by the Ministry of the Domestic Affairs together with the National Association of Italian Municipalities. This includes a criterion for assigning places for each municipality "per 1.000 inhabitants" for almost all municipalities over 2.000 inhabitants.

\section{Intercultural mediation}

in the residential services for refugees and asylum seekers

The UNHCR (2019) defines a refugee "someone who has been forced to flee his or her country because of persecution, war or violence". His fear of persecution for reasons of race, religion, nationality, political opinion or membership in a particular social group should be well-founded and should be real obstacles for returning home. The fact that two-thirds of all refugees worldwide come from Syria, Afghanistan, South Sudan, Myanmar and Somalia proves that war and ethnic, tribal and religious violence are leading causes of refugees fleeing their countries. "When people flee their own country and seek sanctuary in another country, they apply for asylum - the right to be recognised as a refugee and receive legal protection and material assistance. An asylum seeker must demonstrate that his or her fear of persecution in his or her home country is well-founded" (UNHCR, 2019).

Refugees and asylum seekers are people who, due to the peculiarity of their condition and personal life stories, turn to the reception services the request to meet their most immediate needs and to establish the basis for an integration into Italian society that can embrace a wider temporal dimension. Marco Catarci (2019) argues that integration processes must involve and converge multiple aspects of the life of individuals, considering in particular:

- economic integration, which primarily concerns the achievement of economic autonomy, through access to decent employment;

- social inclusion, through the construction and autonomous management of relationships, participation in associations, the use of free time, the access to decent accommodation;

- cultural integration, through the acquisition of language skills, the access to training opportunities and the development of cultural mediation processes;

- political integration, through paths of full participation in the life of society and citizenship.

According to Marco Catarci, success in these parallel and integrated paths largely depends on the effective satisfaction of some of the most pressing needs that asylum seekers express from the first moments of their arrival:

- needs for information, orientation and relationship with the services, which consist in the need to be supported by the knowledge, of- 
ten fragmented, inconsistent and incomplete of the territorial services, as well as the effective access to them;

- needs for job integration, which refer to the needs to be accompanied in the path of professional assimilation, on which an overall position of social weakness weighs, which translates into a strong dependence on informal networks for access to information and professional opportunities and in the difficulty of linking professional development with the overall integration project, often due to a legal-administrative vulnerability;

- socio-professional development and promotion needs, which relate to the low or weak employability, towards which accompanying actions must be directed in the development of a professional project in the new context of life;

- cultural needs in a broad sense, which concern both the cultural horizon of origin, and the acquisition of forms and models related to the new context.

The Report on Asylum and Migration in Italy 2018 detects a panorama rich in initiatives for the promotion of integration in its various dimensions. For example, in 2018 the Skills2 work project continued, started by the OIM and funded by the European Commission. The project, addressed to beneficiaries of international protection and asylum seekers, has the objective of facilitating the integration into the labor market by guaranteeing information on the required procedures and the competent services for the recognition of formal, non-formal and informal skills. The project started from the partnership between the OIM national offices of 9 countries (Belgium, Holland, Hungary, Ireland, Italy, Slovakia, Spain, Slovenia, England) and met the collaboration of the Agencies for the recognition and validation of competences, integration agencies, competent ministries, integration services and academic institutions. The project has three main objectives: to develop guidelines on the process of recognition of skills and integration in the labor market during the asylum application phase, on the basis of good practices found in the 9 partner countries and consultations with national stakeholders; to develop a pathfinder to support integration and reception services dedicated to asylum seekers, refugees and employers; to involve the private sector in the formation of a network aimed at promoting the meeting and job match between employers and migrant workers.

In 2018, also the INSIDE project was completed. The aim of the project was to promote the socio-employment integration of the holders of international protection hosted in the SPRAR system, and was carried out within the framework of close coordination between labor, reception and integration policies. INSIDE was a pilot project, funded by the Ministry of Labor and Social Policies, General Directorate for Immigration and Integration Policies, aimed at offering 672 socio-employment placement internships intended for holders of international protection hosted in the SPRAR system.

Other initiatives concerned the provision of 100 scholarships for students with protection, forced to interrupt the study path started in the country of origin, the activation of internship courses in companies aimed at promoting the meeting between professional skills of the holders of international protection and those required by companies, the implementation of activities aimed at promoting the inclusion and integration of first and second generation migrant citizens through sport and to combat forms of discrimination and intolerance.

To conclude this discourse on the needs of refugees and asylum seekers and on how Italian reception structures, in particular the third-level residential ones, try to respond by implementing intercultural mediation initiatives, we are reporting the main results of a research conducted by Laura Cerrocchi (2019) inside one of these structures in the city of Reggio Emilia.

The reception facilities in the city of Reggio Emilia host 405 people, mainly adult men, single women and families. The first objective of the work of the educational operators is the reconquest and development of the individual's autonomy in the various areas of life. In this regard, there are certain areas in which educational work is concentrated: documentation, the link with the Health and Social Services, education and training, work, social inclusion, 
coexistence, relationships with the family of origin. The research considered here has made use of more tools, activities and strategies, combining moments of participant observation, analysis of archival documents, interviews with privileged witnesses and, above all, group conversations-discussions with sixteen young men aged between 21 and 29 years old, from Nigeria, Gambia, Senegal, Cameroon and Mali, asylum seekers and guests who have been staying at the Reggio Emilia facilities for a few months. The discussions were scheduled in four meetings with the following respective thematic nuclei: awareness of the historical-political-economic causes underlying migration; the role of the family in choosing to migrate; the way in which the insertion and permanence in the structures of Reggio Emilia took place and the characteristics of the integration project; the possible involvement in literacy and professional courses, the use of the cultural and social services of the territory, the prospect of return and/or training, work and life planning.

From the discussions emerge portraits of young men who live a present characterized by suffering, linked to experiences of pain and loss and the perception of not being accepted by the society in which they live; to make the situation even more serious, the lack of affective figures of reference, lacerations, traumas, sense of estrangement, experiences of hostility and discrimination often occur. It is therefore important that the structures of the city of Reggio Emilia, in their overall organization and in the daily work of the operators, know how to welcome people who bring with them such experiences and emotional states: for this purpose, it is decisive both to know some characteristics that are part of all the dynamics of migration, and be able to empathize with the specificity of each life story.

Educational operators must be able to deal with the opacity of the subjects who enter the structures, becoming aware of the impossibility of knowing in depth the reasons for their migration and the complexity of the factors that occured when they choosed to migrate. In the structures coexist people who have often lived traumatic events and have heterogeneous reasons for the migration, attributable to family problems (conflicts, lack of resources), political (wars, militancy, absence of rights), economic (unemployment, poverty), social (lack of security, terrorism, violence, discrimination) and cultural (refusal of models considered restrictive) factors.

The choice to migrate is a response to an emergency situation, but also a project that contains long-term expectations. Educational operators must plan and implement interventions on at least three levels:

a) rethinking of migratory experiences;

b) satisfaction of first level and acculturation needs;

c) elaboration and sharing of a life project.

In reference to the latter, the starting point are the expectations of the young migrants, due primarily to the desire to build a future and restructure a life project, also through the re-definition of the self in the present, the integration in the new socio-cultural context and the acquisition of new skills; it is essential to recover one's independence, to be masters of one's destiny and to have the means and opportunities to seize the opportunities. These young men also expect to be able to obtain respect and social recognition, to emancipate and re-build themselves as young men: in work, relationships and affections, thus internalising the success of their migration path.

The pedagogical planning put in place by the operators of the structures to support these expectations develops by interweaving multiple levels of analysis and action and resorting to intercultural mediation strategies that try to apply all the four typologies identified by Margalit Cohen-Emerique (2007): the laison focus, the anti-prejudice strategies, the conflict management and resolution, the attempt to transform institutional approaches. Educational operators act as bridges between migrants and the city of Reggio Emilia, with its services, its inhabitants, its places, its opportunities. Their actions develop in the following areas:

1) first literacy in Italian;

2) training and professional start-up;

3) rethinking of traumatic experiences;

4) socio-cultural integration;

5) financial support. 
A first area of intervention concerns the first literacy and develops through the organization of Italian L2 courses and further moments of individualized and/or small group learning and study, also taking advantage of the help of volunteers. Training and professional start-up are pursued through the offer of internship experiences and apprenticeships with some artisans or local industries, but also through the commitment to volunteer activities in close contact with the local community. The rethinking of traumatic experiences is made possible by psychological support services and by the constant presence of educators, figures of reference and mediation in every aspect and at every moment of the integration process. Financial support, on the other hand, is achieved through the granting of modest sums of money every month, which can be used for small expenses or for accumulating the first savings.

Particular attention is paid to socio-cultural integration, which is promoted in particular through the participation and use of the cultural and social offer of the territory. In this case, young migrants participate in events and initiatives of contact and exchange with the local community (meetings, parties, dinners, etc.), engage in sports activities and collaborations with some local realities, always with the medi- ation of the educational staff of the structures. Furthermore, in informal moments, autonomously, some of them frequent Islamic centers or Christian parishes, libraries and other gathering places. Nevertheless, episodes of racism and perceptions of discrimination continue to be present, making it necessary for operators to have an incisive anti-racism awareness work aimed at the local community and the contexts frequented by migrants.

\section{Conclusion}

The experience of the services of the city of Reggio Emilia confirms how intercultural mediation practices are necessary within all the proposed activities. The meeting between the new citizens arrived from Africa and the local social context is configured as a meeting between two profoundly different entities: it is therefore necessary to operate a constant action of building bridges, to seek and strengthen the contact points and promote reciprocity and exchange. The alternative would be conflict, prejudice, non-integration: it would be a nefarious scenario not only for new arrivals, but also for the indigenous population, which would find itself losing precious enrichment opportunities and slowing down the processes of social and cultural evolution that appear inevitable, as local consequences of global phenomena.

\section{References}

Arvantis, E. (2014). The Intercultural Mediation: A Transformative Journey of Learning and Reflexivity. In Intercultural Mediation in Europe: Narratives of Professional Transformation, ed. E. Arvantis and A. Kameas, Champaign, Illinois, USA, Common Ground Publishing LLC.

Bhabha, H. (1994). The Location of Culture. New York, Routledge.

Blaney McMurtry LLP (2019). Alternative dispute resolution. An introduction to mediation, available at: https://www.blaney.com/sites/default/files/other/adr_introduction.pdf

Catarci, M. (2019). L'inclusione formativa e sociale dei richiedenti e titolari di protezione internazionale. In Narrare la migrazione come esperienza formativa. Strumenti e strategie di comunità e corresponsabilità educativa, ed. L. Cerrocchi, Milan, FrancoAngeli.

Cerrocchi, L., Menozzi, M., Zannoni, F., D’Antone, A., Badii, G. (2019). Narrare la migrazione come esperienza formativa: compiti, strumenti e strategie nel Progetto con i Richiedenti Protezione Internazionale della Cooperativa Sociale e di Solidarietà L'Ovile di Reggio Emilia. In Narrare la migrazione come esperienza formativa. Strumenti e strategie di comunità e corresponsabilità educativa, ed. L. Cerrocchi, Milan, FrancoAngeli.

Cohen-Emerique, M. (2007). Intercultural Mediators: Bridges of Identities. In InterCulture, $153,7-22$. 
Council of Europe (2011). Intercultural Competences in Social Services: Constructing an inclusive institutional culture. Paris, Council of Europe Publishing.

European Migration Network (2019). In Rapporto su Asilo e Migrazione in Italia 2018, available at: https://ec.europa.eu/homeaffairs/sites/homeaffairs/files/15a_italy_annual_policy_report part2_2018_en.pdf

Fokin, V., Baryshnikov, V., Bogoliubova, N., Nikolaeva, J., Ivannikov. I., Portnyagina, M., Ryazantseva, N., Eltc, E., Chernov, I. (2016). Multiculturalism in the Modern World. In International Journal of Environmental \& Science Education, 11 (18), 10777-10787.

Initiative Mediation Support Deutschland (2017). Basics of Mediation: Concepts and Definitions. Berlin, Federal Foreign Office \& Initiative Mediation Support Deutschland (IMSD).

Istat (2001). In Rapporto Istat - $14^{\circ}$ Censimento della popolazione: dati definitivi. Cittadini stranieri residenti.

Istat (2016). In Cittadini Stranieri. Popolazione residente e bilancio demografico al 31 dicembre 2015.

Istat (2017). In Bilancio demografico nazionale al 31 dicembre 2016.

Kalantzis, M., Cope, W. (2012). New Learning: Elements of a Science of Education. New York, Cambridge University Press.

Lefebvre, H. (1991). The Production of Space. Oxford, Blackwell Publishers.

Militello, V., Spena, A. (2015). Il traffico di migranti: Diritti, tutele, criminalizzazione. Torino, Giappichelli.

Panikkar, R. (1995). Invisible Harmony. Essays on Contemplation and Respopnsibility. Minneapolis, Fortress Pess.

Rick, A. (1997). What Space Makes of Us: Thirdspace, Identity Politics, and Multiculturalism. American Educational Research Association Conference. Chicago, IL, UCLA.

Rosoli, G. (1978). Un secolo di emigrazione italiana 1876-1976. Roma, Cser.

Skordoulis, C. \& Arvanitis, E. (2008). Space conceptualisation in the context of postmodernity: Theorizing spatial representation. In The International Journal of Interdisciplinary Social Sciences, 3(6), 105-113.

Stier, J. (2006). Internationalisation, intercultural communication and intercultural competence. In Journal of Intercultural Communication, 11, 1-11.

UNHCR (2019). What is a Refugee? Available at: https://www.unrefugees.org/refugee-facts/ what-is-a-refugee/

Thomas, D. (1996). Transcultural Space and Transcultural Beings. Oxford, Westview Press.

Townsend, J. (2002). The Intercultural Mediator: The nexus of practice and theory, available at: http://www.agreementswork.com/TheInterculturalMediator.php

United Nations (2012). Guidance for Effective Mediation. New York, United Nations.

Villa, M., Emmi, V., Corradi, E. (2018). Migranti: la sfida dell'integrazione. Milan, ISPI/ CESVI. 


\title{
Межкультурная медиация
}

\section{в отношении беженцев в Италии}

\section{Федерико Заннони}

Болонский университет

Италия, Болонья

\begin{abstract}
Аннотация. Данная статья направлена на раскрытие концепции и представление практики поликультурной медиации, опираясь на ее базовое определение и области возможного применения.

На основе анализа особенностей поликультурного итальянского общества, связяанных с прибытием беженцев и вынужденных переселенцев из Африки, представлены принципы и передовые практики поликультурной медиации, реализуемой службами приема и интеграции мигрантов.

Наконец, предъявлены результаты исследования, проведенного на базе социальных служб города Реджо-Эмилия, в частности, посредством групповых дискуссий с молодыми мужчинами-беженцами, проживающими в специально предоставленном социальном жилье среди коренного населения.
\end{abstract}

Ключевые слова: межкультурная медиация, миграция, беженцы, Италия.

Научная специальность: 22.00.00 - социологические науки. 